\title{
Management of ileocecal Crohn's disease during surgical treatment for acute appendicitis: a systematic review
}

\author{
Abel Botelho QUARESMA ${ }^{1}$, Eron Fabio MIRANDA ${ }^{2}$ and Paulo Gustavo KOTZE²,3
}

Received: 1 May 2021 Accepted: 23 June 2021

\begin{abstract}
Background - In many patients, the diagnosis of Crohn's disease (CD) is made during surgery for appendicitis in urgent settings. Intraoperative diagnosis can be challenging in certain cases, especially for less experienced surgeons. Objective - Review of the literature searching for scientific evidence that can guide surgeons through optimal management of ileocecal CD found incidentally in surgery for acute appendicitis (AA). Methods - Included studies were identified by electronic search in the PubMed database according to the Preferred Items of Reports for Systematic Reviews and Meta-Analysis (PRISMA) guidelines. The quality and bias assessments were performed by Methodological Index for Non-Randomized Studies (MINORS) criteria for non-randomized studies. Results - A total of 313 studies were initially identified, six of which were selected (all retrospective) for qualitative assessment (two studies were comparative and four only descriptive case series). Four studies identified a high rate of complications when appendectomy or ileocolectomy were performed and in only one, there was no increased risk of postoperative complications with appendectomy. In the sixth study, diarrhea, previous abdominal pain, preoperative anemia and thrombocytopenia were independent predictors for CD in patients previously operated for suspected AA. Conclusion-Despite the paucity of data and low quality of evidence, a macroscopically normal appendix should be preserved in the absence of complicated disease when CD is suspected in surgery for AA. Ileocecal resections should be reserved for complicated disease (inflammatory mass, ischemia, perforation or obstruction). Further prospective studies are needed to confirm these claims.
\end{abstract}

Keywords - Crohn disease; colorectal surgery; appendectomy; systematic review.

\section{INTRODUCTION}

Crohn's disease (CD) is associated to an individual and phenotypic heterogeneity ${ }^{(1)}$ despite various diagnostic methods (clinical, endoscopic, radiological and histological), its definitive diagnosis can be complex in many situations. In urgent settings, the challenge can be more significant, as patients with ileocecal CD not previously diagnosed often have right lower quadrant (RLQ) pain as an initial manifestation and clinical and laboratory parameters which are often compatible with acute appendicitis (AA) ${ }^{(2)}$ unexpected inflammatory masses of uncertain etiology and indistinguishable appearance can also be found in emergency surgical procedures, further complicating surgeons' intraoperative decisions ${ }^{(3)}$.

In many patients, the diagnosis of $\mathrm{CD}$ is made during emergency surgery on suspicion of AA. Often an inflammatory condition reaching the appendix and the ileocecal region can place $\mathrm{CD}$ as a differential diagnosis. Intraoperative diagnosis can become a challenge in some cases, especially for less experienced surgeons $s^{(3-5)}$.

Intraoperative surgical decisions can be controversial regarding the management of acute presentation of $\mathrm{CD}$ in the ileocecal region, mimicking AA. Paradoxically, in a British survey, surgeons seemed more conservative in their approach as compared to gastroenterologists in CD management under these conditions ${ }^{(6)}$.
In this scenario, surgeons need to develop the ability to decide what to do and not to do in order to minimize postoperative complications. The aim of this systematic review is to analyze the scientific evidence wich can guide surgeons towards optimal management of ileocecal CD found incidentally in surgical procedures of suspected AA.

\section{METHODS}

\section{Search strategy}

This qualitative systematic review (SR) was performed according to the Reporting Preferred Item Guidelines for Systematic Reviews and Meta-Analysis (PRISMA). A complete (unregistered) protocol for SR was performed to meet the objectives. Included studies were identified by electronic search in the Medline database via PubMed [https://www.ncbi.nlm.nih.gov/pubmed/], a comprehensive bibliographic search was carried out on August 19, 2020 followed by an update on March 12, 2021, by title and summary (title and abstract) using Health Sciences Descriptors (DeCS) developed from the Medical Subject Headings (MeSH) of the US National Library of Medicine (NLM) in the following sequence name: ((appendicitis [title/abstract]) OR (appendicectomy [title/ abstract])) AND (Crohn's disease [title/abstract]).

Declared conflict of interest of all authors: none

Disclosure of funding: no funding received

${ }^{1}$ Universidade do Oeste de Santa Catarina, Joaçaba, SC, Brasil. ${ }^{2}$ Pontifícia Universidade Católica do Paraná, Unidade de Cirurgia Colorretal, Curitiba, PR, Brasil. ${ }^{3}$ Pontifícia Universidade Católica do Paraná, Faculdade de Medicina, Programa de Pós-Graduação em Ciências da Saúde, Curitiba, PR, Brasil.

Corresponding author: Abel Botelho Quaresma. E-mail: abel@proctoclinic.com.br 


\section{Eligibility and inclusion/exclusion criteria}

All terms were searched as keywords, when available. The search results were selected for potentially relevant studies by title and abstract, followed by the full-text review of the pre-selected publications.

References to relevant publications such as reviews have been searched and cross-referenced manually to appropriate inclusion of additional publications. Studies which were published in full in the peer-reviewed literature were included and review articles, editorials, guidelines, errata and case reports were excluded.

\section{Selection of studies and data collection process}

The citations generated by electronic searches on Pubmed were imported into another specific database. After removal of duplicates, the title and abstract of all identified citations were reviewed (first check). The full publications of potentially relevant citations included in the first check were subsequently examined (second check) for inclusion/exclusion, applying the eligibility criteria listed above. Any disagreements related to eligibility or interpretation were resolved by consensus.

Data extraction and quality control were performed independently by two reviewers (Quaresma AB, Miranda EF), with additional corroboration by an expert reviewer (Kotze PG). Any disagreements were resolved by consensus.

\section{Evaluation of the methodological quality of the studies}

The methodology of the selected studies was assessed using the Methodological Index for Non-Randomized Studies (MINORS) ${ }^{(7)}$ for non-randomized clinical trials and observational studies. The risk of bias was judged to be "0" (not reported), "1" (reported, but inappropriately) or "2" (reported appropriately). The ideal final score would be 16 for non-comparative studies and 24 for comparative studies.

\section{RESULTS}

The PRISMA flowchart derived from the search is illustrated in FIGURE 1. A total of 298 articles were found in the PubMed database, with another 15 articles being added with internet search and analysis of citations, with a total of 313 articles initially evaluated. From those, four were excluded for being duplicates and 254 for not having a direct relationship with the subject. From the 55 that were initially considered, 49 were excluded after reading the full text ( 44 for not focusing on the proposed topic and five for being case reports). Six studies were finally included for the qualitative analysis. TABLE 1 summarizes the included studies with their main characteristics.

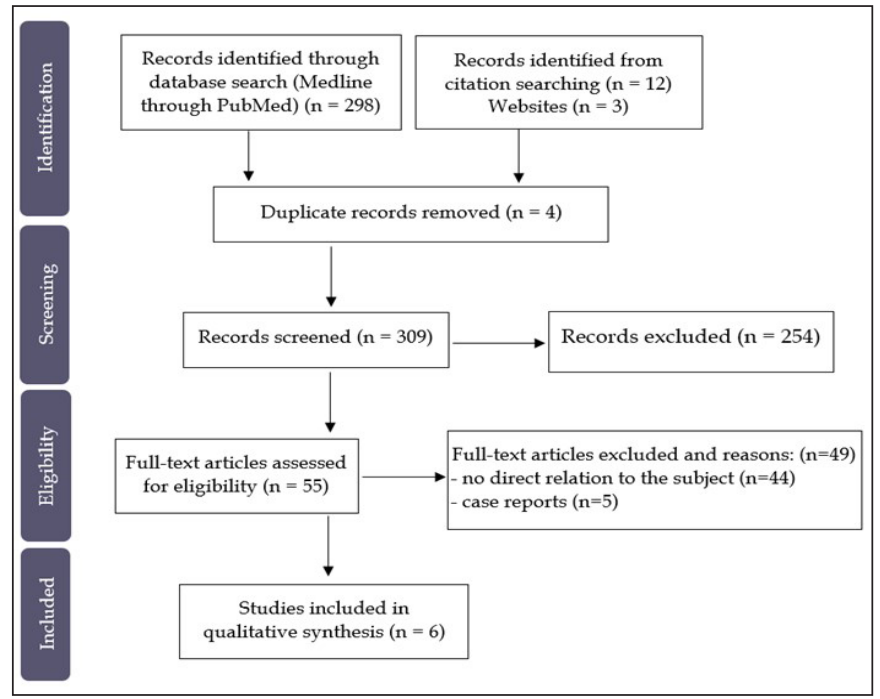

FIGURE 1. Systematic review PRISMA flow diagram.

TABLE 1. Included studies.

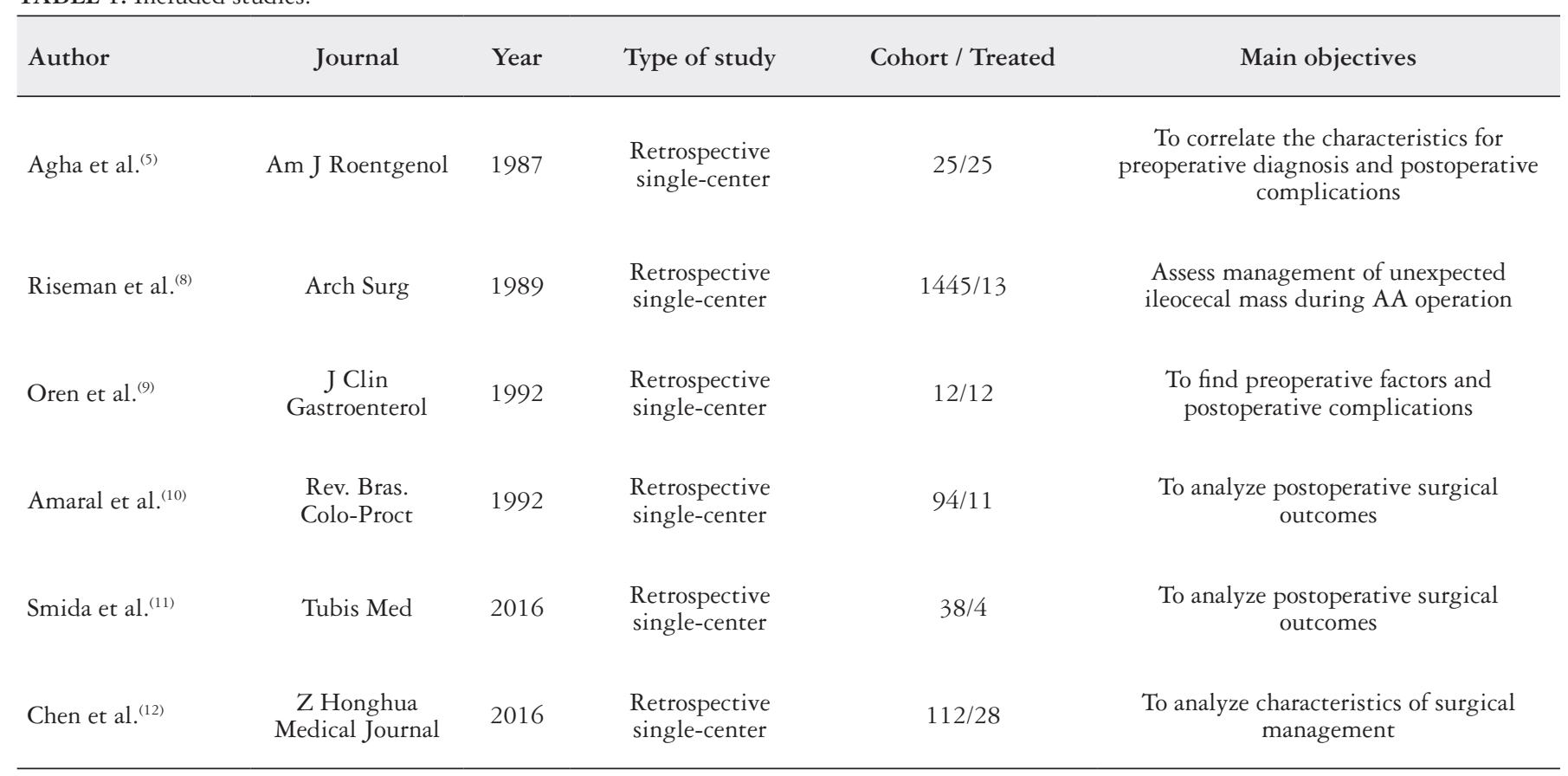

AA: acute appendicitiss. 
Agha et al. ${ }^{(5)}$, analyzed 25 patients with AA as the initial manifestation of $\mathrm{CD}$, being responsible for $1.8 \%$ of all patients with $\mathrm{AA}$ who underwent surgery. Preoperative radiological studies showed abnormalities in 18/25 (72\%) cases, indicating the presence of AA or periapendicular abscess, but not the specific diagnosis of $\mathrm{CD}$ as the main cause for surgical indication. Histopathological evidence of isolated, transmural or granulomatous AA was found in 20 patients; two of them had local recurrence within 3 years after surgery, while another 18 remained asymptomatic during follow-up of up to 8 years. In the other five patients, CD caused AA with concomitant inflammation of the cecum or terminal ileum; three of these cases were complicated by progressive granulomatous ileocolitis in 2 years.

Riseman et al..$^{(8)}$, identified 13 patients who had a right hemicolectomy performed for unexpected inflammatory masses in which neoplasms, diverticular disease or inflammatory bowel disease could not be differentiated from severe AA during laparotomy. Seven patients had a diagnosis of appendicular phlegmon on the final pathological examination. The other patients had $\mathrm{CD}$, typhlitis or neoplasia. The right hemicolectomy was performed with 7\% morbidity and $7 \%$ mortality in all patients.

Oren et al..$^{(9)}$, studied 12 patients who underwent laparotomy for suspected AA in which $\mathrm{CD}$ was found in the terminal ileum. Appendectomy was performed on all, although only four patients had a severely inflamed appendix. Postoperative complications, abscesses or fistula, occurred in $4(33 \%)$ patients. Detailed investigation of the records revealed some preoperative diagnostic clues for a diagnosis of $\mathrm{CD}$ : history of recurrent abdominal pain and/ or diarrhea $(83 \%)$, physical examination revealing normal temperature $(50 \%)$ and laboratory results compatible with a chronic process such as microcytic anemia (33\%) and hypoproteinemia/ hypoalbuminemia/hypocholesterolemia (50\%).

Amaral et al. ${ }^{(10)}$, studied 94 patients with CD, of which $11(11.7 \%)$ had a suggestive picture of AA who were compared to controls with an incidence of appendicitis of $11 \%$. Three patients presented with AA prior to the diagnosis of $\mathrm{CD}$. All were submitted to appendectomy. In three patients the condition of AA was simultaneous to the diagnosis. Two of these patients underwent appendectomy and one underwent resection of the terminal ileum and cecum with primary anastomosis. In five patients, AA occurred on average 5.8 years after the diagnosis of $\mathrm{CD}$. Four patients underwent appendectomy and one underwent resection of the terminal ileum and cecum with primary anastomosis. All operated patients for suspected AA, regardless of the surgical procedure, presented uneventful evolution.

Smida et al. ${ }^{(1)}$, retrospectively evaluated 38 patients, who underwent a surgical resection for $\mathrm{CD}$. The indications, the type of intervention, duration of preoperative and postoperative complications and the general prognosis of the disease were studied. Of the 38 patients with $\mathrm{CD}$ who needed surgery, 17 underwent emergency surgery, and in 11 surgery was the reason which made the diagnosis possible. The average duration of symptoms before surgery was 1.5 years. The most common indication for emergency surgery was acute intestinal obstruction $(\mathrm{n}=6)$ followed by perforation and peritonitis $(n=5)$. A misdiagnosis of appendicitis was found in four patients and severe acute colitis complicated by undiagnosed $\mathrm{CD}$ was found in two cases. Conventional open surgery was performed for 15 patients. Ileocolic resection was the most common intervention. There was one death and five cases with postoperative complications. The average postoperative hospital stay was 14 days (range, 4 to 60 days). Six patients required a second operation during follow-up.

Chen et al. ${ }^{(12)}$, in the study with the largest sample of patients, described the clinical manifestations and independent diagnostic predictive factors for $\mathrm{CD}$ in patients initially diagnosed as appendicitis and treated by surgery. Twenty eight patients were identified (Group CD) and, for each case of CD, three controls with a confirmed diagnosis of appendicitis were matched [Group appendicitis $(n=84)]$. Clinical manifestations and results of laboratory tests of the two groups were analyzed with multivariable logistic regression to determine independent diagnostic predictive factors for $\mathrm{CD}$ initially misdiagnosed as AA. A total of 112 patients were included, with a male/female ratio of 1.04:1 (57:55 and average age of 36 years. Multivariate analysis demonstrated that the change in bowel habits and stool consistency (OR $=36.712,95 \% \mathrm{CI}: 1.672-806,103$, $P=0.022)$, medical history of chronic abdominal pain or diarrhea (OR=60.142, 95\% CI: 4.501-803.573, $P=0.002$ ), lower preoperative hemoglobin level (OR=0.909, 95\%CI: $0.858-0.963, P=0.001)$ and higher platelet count (OR=1.027, 95\%CI: $1.007-1.047, P=0.008)$ were independent predictive factors for $\mathrm{CD}$.

TABLE 2 describes the categorization by the MINORS criteria

TABLE 2. Methodological Index for non-randomized studies ${ }^{(13)}$ for evaluation of non-randomized clinical trials and observational studies included in the systematic review.

\begin{tabular}{|c|c|c|c|c|c|c|}
\hline MINORS criteria & $\begin{array}{c}\text { Agha } \\
1987^{(5)}\end{array}$ & $\begin{array}{c}\text { Riseman } \\
1989^{(8)}\end{array}$ & $\begin{array}{c}\text { Oren } \\
1992^{(9)}\end{array}$ & $\begin{array}{l}\text { Amaral } \\
1992^{(10)}\end{array}$ & $\begin{array}{l}\text { Smida } \\
2016^{(11)}\end{array}$ & $\begin{array}{c}\text { Chen } \\
2016^{(12)}\end{array}$ \\
\hline Inclusion of consecutive patients & 2 & 2 & 2 & 2 & 2 & 2 \\
\hline Endpoints appropriate to the aim the study & 2 & 2 & 1 & 2 & 2 & 2 \\
\hline Unbiased assessment of the study endpoint & 2 & 1 & 1 & 2 & 1 & 2 \\
\hline Follow-up period appropriate to the aim the study & 2 & 2 & 2 & 2 & 2 & 2 \\
\hline Prospective calculation of the study size & 0 & 0 & 0 & 0 & 0 & 1 \\
\hline \multicolumn{7}{|l|}{ Additional criteria in the case of comparative study } \\
\hline An adequate control group & - & - & - & 1 & - & 2 \\
\hline Contemporary groups & - & - & - & 2 & - & 2 \\
\hline Baseline equivalence of groups & - & - & - & 2 & - & 2 \\
\hline Adequate statistical analyses & - & - & - & 0 & - & 2 \\
\hline
\end{tabular}

The items are scored 0 (not reported), 1 (reported but inadequate) or 2 (reported and adequate). The global ideal score being 16 for non-comparative studies and 24 for comparative studies. 
for the six included studies. As noted, most studies have a significant bias, demonstrating the controversy of the topic. Comparative studies had higher rates, but far from the maximum score for quality evidence.

\section{DISCUSSION}

Acute appendicitis remains the most common cause of emergency abdominal surgery ${ }^{(14)}$. CD commonly affects a similar age group and has a similar initial clinical condition ${ }^{(15)}$. Thus, it is essential to quickly establish the diagnosis so that the correct treatment can be started as early as possible. According to a review evaluating 74 articles with 2007 patients, rates of incorrect diagnoses and postoperative complications in the past two decades have remained high $^{(16)}$. The percentage of patients with CD diagnosed incorrectly before surgery was $50.8 \pm 30.9 \%(578 / 1,268)$. Authors reported that large reference centers have a relatively better capacity for surgical treatment than centers with less experience. When surgical treatment is indicated for suspected AA, physicians should be aware of the possibility of diagnostic difficulties and complications due to poorly indicated or not properly conducted surgery ${ }^{(17,18)}$. Thus, postponing surgery in $12 / 24 \mathrm{~h}$ in clinical conditions which are compatible with uncomplicated appendicitis does not increase complication rates and may eventually help in reducing errors in differential diagnosis ${ }^{(19)}$.

This systematic review identified only 6 articles dealing specifically with the subject, most of them with limited sample and low level of evidence. Chen et al. ${ }^{(12)}$, aimed to describe independent diagnostic predictive factors for the correct diagnosis of CD misdiagnosed as appendicitis and treated by surgery. From the 112 patients included, there were no differences related to sex, age and body temperature between the $\mathrm{CD}$ and the appendicitis groups (all $P>0.05$ ). However, changes in bowel habits and stool consistency, medical history of chronic abdominal pain or diarrhea, anemia and increased platelet count have been implicated as predisposing diagnostic factors. These findings can guide surgeons towards a greater suspicion of a CD diagnosis, which can assist in better surgical planning in the preoperative period.

Even with the preoperative diagnosis of AA, intraoperative findings of an inflammatory process in the cecal region is sometimes difficult to differentiate from other causes, given that complicated AA can also cause an intense inflammatory process in this topography. It is up to the surgeon to consider the diagnostic hypothesis of $\mathrm{CD}$, as well as other diseases which affect the terminal ileum, such as infectious or parasitic enteritis (cytomegalovirus, salmonellosis, tuberculosis, actinomycosis, yersiniosis $)^{(2,20)}$. The presence of a mass in the ileocecal and appendicular region should make the surgeon think equally about the possibility of inflammation and neoplasia from the cecum or the appendix ${ }^{(21)}$. Periapendicular abscesses can also be found in neoplasms ${ }^{(22)}$. In such controversial situations, (especially in the presence of sepsis or perforation), intestinal resection by laparoscopy or even the need for conversion to laparotomy may be necessary and the diagnosis will only be established in the histopathological report after a complete analysis of the resected surgical specimen ${ }^{(23)}$.

Complicated appendicitis can be managed laparoscopically by experienced surgeons, with significant advantages including lower overall complications, readmission and small bowel obstruction rates, surgical site infections and faster recovery. Laparoscopy for complicated appendicitis can be performed with low-cost equip- ment, leading to significantly lower overall costs as compared to open surgery, in association with shorter duration of hospital $\operatorname{admission}^{(19)}$.

According to the "2020 update to WSES Jerusalem guideline"(24), the 2010 guidelines of the Society of American Gastrointestinal and Endoscopic Surgeons (SAGES) and the 2016 guideline of the European Association of Endoscopic Surgery (EAES), an appendectomy is recommended in the case of a normal-looking appendix during surgery for suspected AA. On the other hand, Sørensen et al., performed a retrospective analysis of patients undergoing diagnostic laparoscopy due to the clinical suspicion of AA where no other pathology was found, and the appendix was not removed $^{(25)}$. From 271 included patients, $56(20.7 \%)$ were readmitted with RLQ pain after an average time of 10 months. Twenty-two $(8.1 \%)$ patients underwent a new laparoscopic procedure, and the appendix was removed in 18, of which only one had histological signs of inflammation. Based on the results of this study, authors did not consider it necessary to remove a macroscopically normal appendix during laparoscopy for clinical suspicion of AA. Despite this, authors of the "Jerusalem guideline" of 2020, recommended the removal of the appendix if it appears "normal" during surgery and no other disease is found in symptomatic patients [Quality of evidence: low; recommendation strength: weak; $2 \mathrm{C}]^{(24)}$. It is important to note that the aforementioned considerations refer to overall clinical scenarios, and not to suspected $\mathrm{CD}$, which can alter the recommendations according to the severity of associated inflammation.

In the European consensus on $\mathrm{CD}$ surgery by the European Crohn's and Colitis Organization (ECCO), the authors suggest that when ileitis is identified without associated complications and the appendix is not affected by an inflammatory process, the terminal ileum or even the appendix should not be resected, since in uncomplicated $\mathrm{CD}$, with no signs of dilation or penetrating disease, medical treatment is usually indicated. Appendectomy in these cases is strongly contraindicated, due to a high risk of intraabdominal septic complications and fistulas ${ }^{(26)}$.

$\mathrm{CD}$ is often associated with characteristic macroscopic findings, such as the proliferation of mesentery fat involving the intestinal loops ("creeping fat"), hardened consistency and areas of proximal dilation, among others. In cases of phlegmons, blocked perforations or abscesses, or in cases with associated intestinal partial or total obstruction, an ileocecal resection is indicated. Whenever possible, a primary anastomosis should be performed (mostly in patients with good nutritional status and adequate local conditions). However, proximal diversion with ileostomy or double-stoma may be necessary in patients with poor clinical conditions (sepsis, hemodynamic instability, previous use of corticosteroids, suspected malnutrition) and unfavorable intraoperative findings (peritonitis and local technical difficulties) $)^{(27)}$.

The diversity and heterogeneity of the recommendations demonstrate the controversy of the topic and the complex dilemma that surgeons face when finding a normal appendix in these cases. It is also worth mentioning the scarcity of studies with solid evidence on the topic, such as those captured in this systematic review, in addition to the lack of specific guidelines on how to proceed surgically in an emergency situation in the close AA x CD relationship. Thus, a therapeutic algorithm based on the current evidence is suggested, which can serve as a guide for surgeons who may face this scenario in daily practice (FIGURE 2).

This qualitative SR is associated to some limitations which must 


\section{Terminal ileitis and suspicion of acute appendicitis}

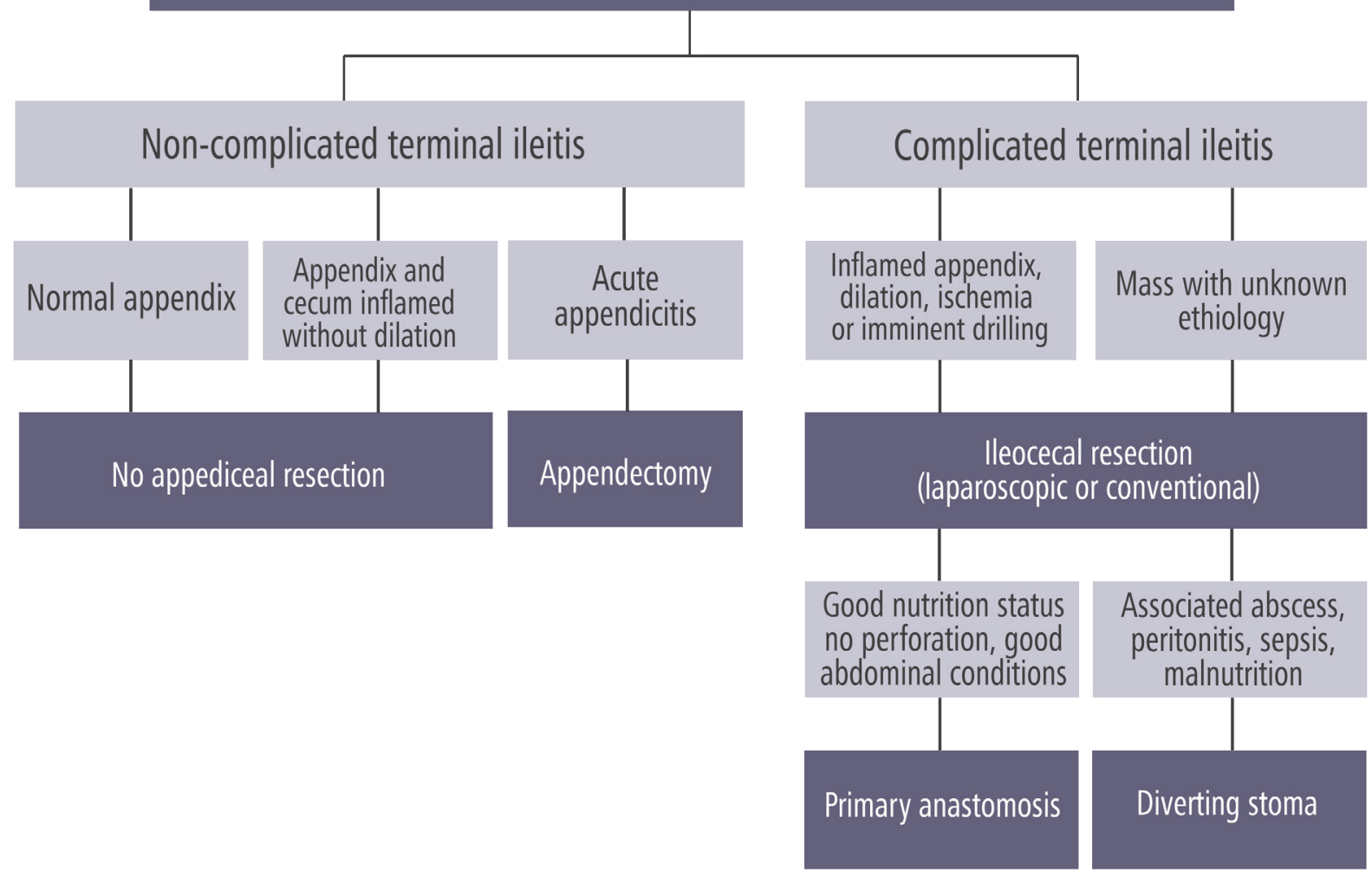

FIGURE 2. Therapeutic algorithm based on the current evidences.

be considered when interpreting the results. The literature search demonstrated a scarcity of articles with good quality of evidence. Most studies are retrospective and purely descriptive, with limited patient samples. Only two studies compared groups, but were associated with important biases. Thus, a quantitative study with meta-analysis was not recommended due to the extreme diversity in methodologies and in included variables in the studies. In addition, there is a considerable number of case reports and reviews over the topic of surgery in AA and $\mathrm{CD}$, but the correlation is difficult because they have considerable diversity in relation to numerous differential diagnoses, making it impossible to correctly assess a cause and effect relationship.

In summary, there is a scarce number of specific studies which analyzed results related to the management of ileocecal $\mathrm{CD}$ in situations of suspected AA, with small samples and low quality evidence. More comparative studies with a larger number of cases are needed to better elucidate the issue. It is suggested that in the presence of an uncomplicated inflammatory process in the RLQ with suspected $C D$, the appendix should not be removed. In the presence of a mass, ischemia, fistula or obstruction, an ileocecal resection is recommended and the decision between a primary anastomosis or a diverting stoma is individualized, considering intraoperative conditions, the nutritional status and the presence of septic conditions. Individualization of treatment must be performed according to the surgeons' experience, the patients' condition and the degree of inflammatory involvement.

\section{Authors' contribution}

Quaresma AB, Miranda EF and Kotze PG designed the review and drafted the paper. All authors gave important intellectual contribution and reviewed the final version of the manuscript.

\section{Orcid}

Abel Botelho Quaresma: 0000-0002-3985-7402.

Eron Fabio Miranda: 0000-0003-4011-5112.

Paulo Gustavo Kotze: 0000-0002-2053-5315. 
Quaresma AB Miranda EF, Kotze PG. Manejo da doença de Crohn ileocecal como achado incidental em cirurgia de urgência para apendicite aguda: uma revisão sistemática. Arq Gastroenterol. 2021;58(4):560-5.

RESUMO - Contexto - Em muitos pacientes, o diagnóstico da doença de Crohn (DC) é feito durante uma cirurgia de urgência por suspeita de apendicite. O diagnóstico intraoperatório pode ser desafiador em certos casos, especialmente para cirurgiões menos experientes. Objetivo - Revisar a literatura em busca de evidências científicas que possam orientar os cirurgiões no manejo otimizado da DC ileocecal encontrada incidentalmente na cirurgia de apendicite aguda (AA). Métodos - Os estudos incluídos foram identificados por busca eletrônica no banco de dados PubMed de acordo com as diretrizes Itens Preferidos de Relatórios para Revisões Sistemáticas e Meta-Análise (PRISMA). As avaliações de qualidade e viés foram realizadas pelos critérios Índice Metodológico para Estudos Não Randomizados (MINORS). Resultados - Foram identificados inicialmente 313 estudos, dos quais seis foram selecionados (todos retrospectivos) para avaliação qualitativa (dois estudos eram comparativos e quatro apenas séries de casos descritivos). Quatro estudos encontraram uma alta taxa de complicações quando a apendicectomia ou ileocolectomia foram realizadas e em apenas um, não houve aumento do risco de complicações pós-operatórias com a apendicectomia. No sexto estudo, diarreia, dor abdominal prévia, anemia pré-operatória e trombocitopenia foram fatores preditivos independentes para DC em pacientes operados previamente por suspeita de AA. Conclusão - Apesar da escassez de dados e da baixa qualidade das evidências, recomenda-se que um apêndice macroscopicamente normal seja preservado na ausência de doença complicada quando há suspeita de DC na cirurgia de AA. As ressecções ileocecais devem ser reservadas para doenças complicadas (massa inflamatória, isquemia, perfuração ou obstrução). Mais estudos prospectivos são necessários para confirmar essas afirmações.

Palavras-chave - Doença de Crohn; cirurgia colorretal; apendicectomia; revisão sistemática.

\section{REFERENCES}

1. Roda G, Ng SC, Kotze PG, Argollo M, Panaccione R, Spinelli A, et al. Crohn's disease. Nat Rev Dis Prim. 20202;6:22.

2. Gionchetti P, Dignass A, Danese S, Dias FJM, Rogler G, Lakatos PL, et al. 3 rd European evidence-based consensus on the diagnosis and management of Crohn's disease 2016: Part 2: Surgical management and special situations. J Crohn's Colitis. 2017;11: 135-49.

3. Guven H, Koc B, Saglam F, Bayram IA, Adas G. Emergency right hemicolectomy for inflammatory cecal masses mimicking acute appendicitis. World J Emerg Surg. 2014;9:1-5.

4. Yang SS, Gibson P, McCaughey RS, Arcari FA, Bernstein J. Primary Crohn's disease of the appendix. Report of 14 cases and review of the literature. Ann Surg. 1979;189:334-9.

5. Agha FP, Ghahremani GG, Panella JS, Kaufman MW. Appendicitis as the initial manifestation of Crohn's disease: Radiologic features and prognosis. Am J Roentgenol. 1987; 149:515-8.

6. Shariff U, Narula H, Speake W, Brown S. Terminal ileal Crohn's disease: Conservative surgeon and aggressive physician? Color Dis. 2009;11:522-3.

7. Slim K, Nini E, Forestier D, Kwiatkowski F, Panis Y, Chipponi J. Methodological index for non-randomized studies (Minors): Development and validation of a new instrument. ANZ J Surg. 2003;73:712-6.

8. Riseman JA, Wichterman K. Evaluation of Right Hemicolectomy for Unexpected Cecal Mass. Arch Surg. 1989;124:1043-4.

9. Oren R RD. Preoperative clues to Crohn's disease in suspected, acute appendicitis. Report of 12 cases and review of the literature. J Clin Gastroenterol. 1992;306-10.

10. Amaral E, Ribeiro M, Larangeira L, Teixeira MG, Brunetti C, Habr-gama A. Doença de cröhn e apendicite. Rev.bras.Colo-Proct. 1993;13:91-3.

11. Smida M, Miloudi N, Hefaiedh R, Zaibi R. Les urgences chirurgicales dans la maladie de Crohn. Tunis Med. 2016;94:210-5.

12. Chen F, Wu H, Wu Y Mao R, Zhang S, Feng T, et al. [Clinical manifestations of Crohn's disease misdiagnosed as appendicitis]. Zhonghua yi xue za zhi. 2016;96:792-5. doi: 10.3760/cma.j.issn.0376-2491.2016.10.009.

13. Slim K, Nini E, Forestier D, Kwiatkowski F, Panis Y, Chipponi J. Methodological index for non-randomized studies (Minors): Development and validation of a new instrument. ANZ J Surg. 2003;73:712-6.

14. Cheluvappa R, Thomas DG, Selvendran S. The role of specific chemokines in the amelioration of colitis by appendicitis and appendectomy. Biomolecules. 2018;8:1-13.

15. Bass J, Goldman J, Jackson M, Gasior A, Sharp S, Drews A, et al. Pediatric crohn disease presenting as appendicitis: Differentiating features from typical appendicitis. Eur J Pediatr Surg. 2012;22:274-8.
16. Yu Q, Mao R, Lian L, Ng SC, Zhang S, Chen Z, et al. Surgical management of inflammatory bowel disease in China: A systematic review of two decades. Intest Res. 2016;14:322-32.

17. Hsu WF, Wu CS, Wu JM, Chung CS. Ileal Crohn's disease with perforation misdiagnosed as ruptured appendicitis: A case report. J Formos Med Assoc. 2013;112:652-3

18. Millet I, Alili C, Pages E, Curros Doyon F, Merigeaud S, Taourel P. Infection of the right iliac fossa. Diagn Interv Imaging. 2012;93:441-52.

19. Di Saverio S, Birindelli A, Kelly MD, Catena F, Weber DG, Sartelli M, et al. WSES Jerusalem guidelines for diagnosis and treatment of acute appendicitis. World J Emerg Surg. 2016;11:1-25.

20. Sung Y-N, Kim J. Appendiceal actinomycosis mimicking appendiceal tumor, appendicitis or inflammatory bowel disease. J Pathol Transl Med. 2020;1-6. doi: 10.4132/jptm.2020.05.17

21. West NE, Wise PE, Herline AJ, Muldoon RL, Chopp WV., Schwartz DA. Carcinoid tumors are 15 times more common in patients with Crohn's disease. Inflamm Bowel Dis. 2007;13:1129-34.

22. Mällinen J, Rautio T, Grönroos J, Rantanen T, Nordström P, Savolainen H, et al. Risk of appendiceal neoplasm in periappendicular abscess in patients treated with interval appendectomy vs follow-up with magnetic resonance imaging: 1-year outcomes of the peri-appendicitis acuta randomized clinical trial. JAMA Surg. 2019;154:200-7.

23. Shindholimath V, Thinakaran K, Rao T, Veerappa Y. Laparoscopic management of appendicular mass. J Minim Access Surg. 2011;7:136-40.

24. Di Saverio S, Podda M, De Simone B, Ceresoli M, Augustin G, Gori A, et al. Diagnosis and treatment of acute appendicitis: 2020 update of the WSES Jerusalem guidelines. World J Emerg Surg. 2020;15:1-42.

25. Sørensen AK, Bang-Nielsen A, Levic-Souzani K, Pommergaard HC, Jørgensen $\mathrm{AB}$, Tolstrup $\mathrm{MB}$, et al. Readmission and reoperation rates following negative diagnostic laparoscopy for clinically suspected appendicitis: The "normal" appendix should not be removed - A retrospective cohort study. Int J Surg. 2019;64:1-4.

26. Bemelman WA, Warusavitarne J, Sampietro GM, Serclova Z, Zmora O, Luglio $\mathrm{G}$, et al. ECCO-ESCP consensus on surgery for Crohn's disease. J Crohn's Colitis. 2018;12:1-16.

27. Benoist S, Panis Y, Beaufour A, Bouhnik Y, Matuchansky C, Valleur P. Laparoscopic ileocecal resection in Crohn's disease: A case-matched comparison with open resection. Surg Endosc Other Interv Tech. 2003;17:814-8. 